ISSN 2075-4450

www.mdpi.com/journal/insects/

Review

\title{
Chemical Ecology of the Colorado Potato Beetle, Leptinotarsa decemlineata (Say) (Coleoptera: Chrysomelidae), and Potential for Alternative Control Methods
}

\section{Ludovic Sablon $^{1{ }^{1} *}$, Joseph C. Dickens ${ }^{2}$, Éric Haubruge ${ }^{1}$ and François J. Verheggen ${ }^{1}$}

1 Unité d'Entomologie fonctionnelle et évolutive, Gembloux Agro-Bio Tech, Université de Liège, Passage des Déportés 2, B-5030 Gembloux, Belgium; E-Mails: e.haubruge@ulg.ac.be (E.H.); fverheggen@ulg.ac.be (F.J.V.)

2 Invasive Insect Biocontrol and Behavior Laboratory, Plant Sciences Institute, Henry A. Wallace Beltsville Agricultural Research Center, Agricultural Research Service, United States Department of Agriculture, Beltsville, Maryland, 20705, USA;

E-Mail: joseph.dickens@ars.usda.gov

* Author to whom correspondence should be addressed; E-Mails: ludovic.sablon@doct.ulg.ac.be or entomologie.gembloux@ulg.ac.be; Tel.: +32-081-622423; Fax: +32-081-622312.

Received: 5 October 2012; in revised form: 8 November 2012 / Accepted: 20 November 2012 / Published: 20 December 2012

\begin{abstract}
The Colorado potato beetle (CPB) has been a major insect pest to potato farming for over 150 years and various control methods have been established to reduce its impact on potato fields. Crop rotation and pesticide use are currently the most widely used approaches, although alternative methods are being developed. Here we review the role of various volatile and nonvolatile chemicals involved in behavior changes of CPB that may have potential for their control. First, we describe all volatile and nonvolatile chemicals involved in host plant localization and acceptance by CPB beetles, including glycoalcaloids and host plant volatiles used as kairomones. In the second section, we present the chemical signals used by $\mathrm{CPB}$ in intraspecific communication, including sex and aggregation pheromones. Some of these chemicals are used by natural enemies of CPBs to locate their prey and are presented in the third section. The last section of this review is devoted a discussion of the potential of some natural chemicals in biological control of CPB and to approaches that already reached efficient field applications.
\end{abstract}

Keywords: integrated pest management; aggregation pheromone; antifeedant; attractant; host plant; semiochemical; cropping management 


\section{Introduction}

The Colorado potato beetle (CPB) Leptinotarsa decemlineata (Say), a coleopteran native to Mexico, was first described by Thomas Say in 1824. CPB then dispersed throughout North America in Solanaceae fields [1]. In 1874, the first serious damage in potato fields was reported by Riley [2]. The beetle was reported in Europe for the first time in 1922, probably arriving via cargo ships during World War I and subsequently colonizing all of Europe except for the British Isles and Scandinavia $[3,4]$. Then, CPB continued to expand eastward and has spread now into central Asia and western China [4].

The CPB is an important defoliating pest of potatoes, Solanum tuberosum L., but can also be found on tomatoes or eggplants [5,6]. In late spring, adults emerge from the soil and colonize potato fields in the surroundings. A mated female can lay up to 800 eggs in her lifetime and one, two or even three generations per year can occur depending on climatic conditions [7-9]. During their complete larval stage (3 to 4 weeks), CPB larvae consume approximately $40 \mathrm{~cm}^{2}$ of potato leaves while adults can ingest up to $10 \mathrm{~cm}^{2} /$ day [8].

The most commonly used method of CPB management, the application of insecticides, has resulted in the rapid development of resistance to most of the active substances [10-13]. Other approaches suggested for control of CPB are listed in Table 1. Among these alternative control approaches, crop rotation, a no cost method, can be effective if there are large distances between the newly planted fields and crops of the previous year [14,15]. Delaying planting time has also been commonly used. Physical barriers have not applied because of the time and energy required to establish them. Mechanical control causes undesirable damage and its efficacy should be improved. Prices of biological control are too high for economic use. The use of transgenic crops is an efficient control method but is currently unacceptable to many consumers [16,17]. Recently, RNA interference was suggested as a new control method but it is still in the experimental stage. Given the limitations of the different control methods and requirements of consumers, chemical ecology may prove to be an alternative method for controlling CPB, through the use of antifeedants or attractive and/or repulsive volatile organic compounds (VOC) deployed to modify chemical interactions of CPB with its environment.

Table 1. Different approaches suggested to control the Colorado potato beetle.

\begin{tabular}{lll}
\hline Category & Control Approaches & References \\
\hline Cultural modifications & Crop rotation & {$[14,18]$} \\
& Delayed or early planting & {$[15]$} \\
& Trap crops & {$[15,19]$} \\
Physical barriers & Straw mulch ground cover & {$[20]$} \\
& Traps with plastic trenches & {$[21]$} \\
Mechanical control & Use of propane flamers & {$[22]$} \\
& Vacuum collection devices & {$[23]$} \\
Biological control & Predators or parasitoids & {$[24,25]$} \\
& Nematodes & {$[26,27]$} \\
& Fungi & {$[28]$} \\
Genetical modifications & Transgenic plants with Bacillus thuringiensis & {$[29,30]$} \\
Molecular biology & RNA interference & {$[31]$} \\
\hline
\end{tabular}




\section{Chemicals Involved in Host Plant Selection}

\subsection{Role of Glycoalkaloids in Acceptance, Repellency and Defense}

The CPB is a specialist herbivore of plants in the family Solanaceae. Hsiao and Fraenkel [32] evaluated the acceptance of 104 plant species and found that only 36 of them were accepted to some degree by CPB. Among the 15 hosts that allow for completion of the CPB life cycle, only four are nonsolanaceous plants. Feeding tests with different host plants showed that while potato is generally preferred [32], CPB populations in some regions showed preference for other Solanaceae [33].

In phytophagous insects, chemical signals have an important role in host plant recognition and acceptance. For CPB, several feeding stimulants (Figure 1) have been identified by Hsiao and Fraenkel [34] as carbohydrates (sucrose, melezitose, glucose and fructose), amino acids (L-alanine, $\gamma$ aminobutyric acid, L-serine, DL- $\alpha$-aminobutyric acid, DL- $\beta$-aminobutyric acid and L-proline), phospholipids (lecithin, phosphatidyl L-serine and inositol phosphatide) and chlorogenic acid [35]. Inorganic salts $\left(\mathrm{KCl}, \mathrm{KH}_{2} \mathrm{PO}_{4}\right.$ and $\left.\mathrm{NaCl}\right)$ may act as co-factors of phagostimulants and enhance feeding [34]. Kunzeaol and ledol, two alcohols present in the leaf surface of potatoes, showed a phagostimulant effect but the concentration applied in bioassays was 5-fold higher than in a natural potato leaf [36].

Potatoes and other solanaceous plants contain glycoalkaloids [37,38] (Figure 2) that are thought to provide resistance against herbivorous insects including CPB [39]. Solanine, chaconine, tomatine [40], leptines [41] and demissines [42] have been identified as deterrents. Hybridization was used to create new potato progenies containing leptines with increased resistance to beetles [43]. Hollister et al. [44] demonstrated a specific dose dependent response to leptine I from a neuron associated with chemosensory hairs on the galea of CPB. Solanine and tomatine did not induce dose dependent responses but modified responses to leptine I and elicited irregular bursts of neural activity. These results are consistent with those of others and provide neural mechanisms for feeding deterrence attributed to these alkaloids [44-46].

Various studies have examined the impact of glycoalkaloids on the development of CPB with equivocal results. Hare [47] tested the addition of glycoalkaloids ( $\alpha$ and $\beta$-solamarine, $\alpha$-tomatine, $\alpha$ chaconine and $\alpha$-solanine) to diets and observed weight gain of larvae after 24 hours. He concluded that larval development was negatively affected by each alkaloid. Kowalski et al.[48] studied the effects of five alkaloids ( $\alpha$-tomatine, $\alpha$-chaconine, $\alpha$-solanine, leptine I and the steroidal aglycone solanidine) on the development of CPB larvae, from hatching to prepupal stage. They highlighted the adverse effects of leptine I and steroidal aglycone solanidine on the development of the larva (weight gain and time to molt). On the other hand, $\alpha$-chaconine (at high concentration) and a mix of $\alpha$ chaconine with $\alpha$-solanine (at concentrations commonly found in $S$. tuberosum) did not affect the larval growth. In 2007, Lyytinen et al. studied three varieties of potatoes in terms of nitrogen content (positive effect on beetle performance expected) and glycoalkaloid concentration (negative effect expected) [49]. Based on larval growth and survival, no significant difference was found in beetle performance related to the glycoalkaloid content of the potato variety. Moreover, Armer [50] showed that fourth instar CPB larvae and adults neither sequester nor metabolize glycoalkaloids (solanine and chaconine). In conclusion, the higher the concentration in glycoalkaloids, the more deterrent the host 
plant. However, the latter studies indicate that glycoalkaloids do not affect survival of larvae and adults.

Figure 1. Feeding stimulants of the Colorado potato beetle, Leptinotarsa decemlineata.

\section{Carbohydrates}

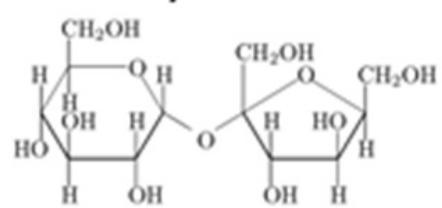

sucrose

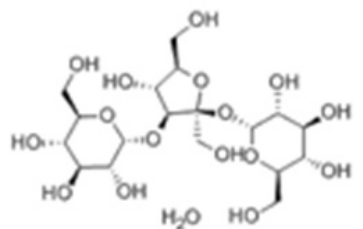

melezitose

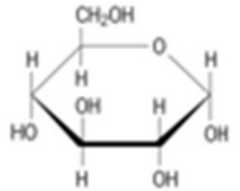

glucose

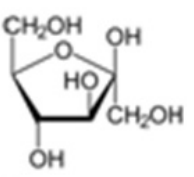

fructose

\section{Amino acids}<smiles>CC(N)C(=O)O</smiles>

L-alanine<smiles>NCCCC(=O)O</smiles>

$\gamma$-aminobutyric acid

Phospholipids

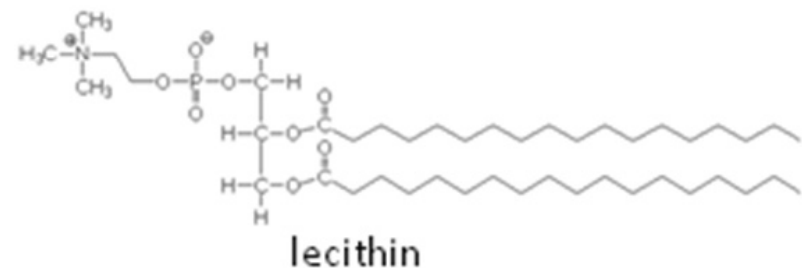<smiles>CCC(N)C(=O)O</smiles>

DL- $\alpha$ aminobutyric acid<smiles>CC(N)CC(=O)O</smiles>

$D L-\beta$ aminobutyric acid

\section{Chlorogenic acid}<smiles>O=C(O)[C@@H]1CC[Te][Te]1</smiles><smiles>O=C(/C=C\c1ccc(O)c(O)c1)OC1CC(O)(C(=O)O)CC(O)C1O</smiles><smiles>[R]C(=O)OCC(COC([R])=O)OP(=O)([O-])OCC(N)C(=O)O</smiles>

phosphatidyl-serine
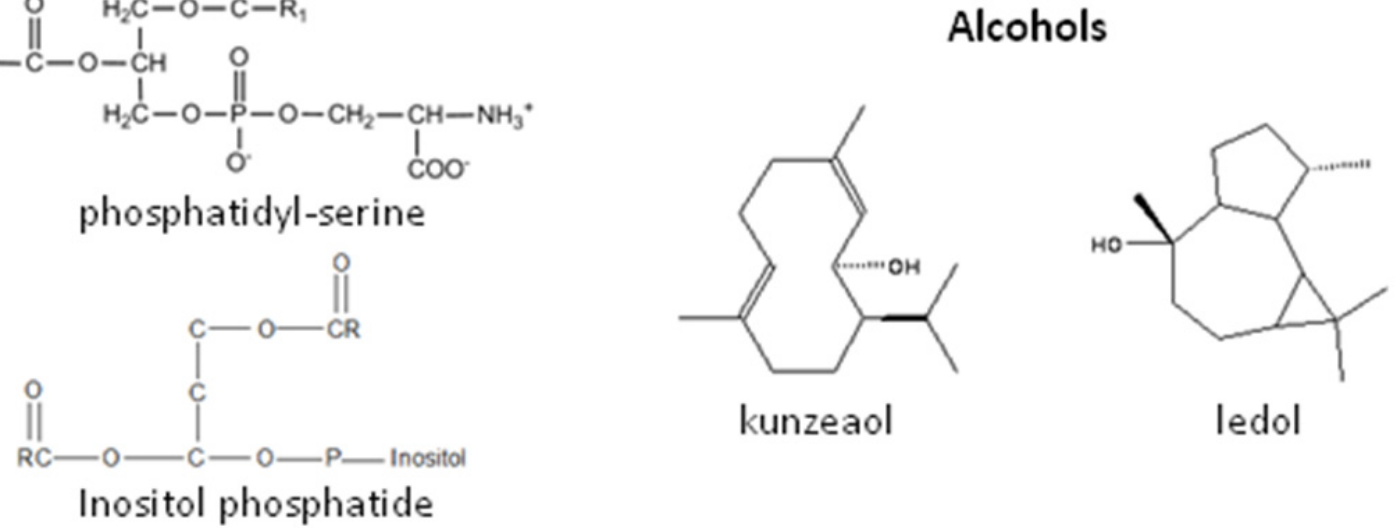

Other chemical defense mechanisms against herbivores in plants have also been reported. For example, Kruzmane et al. [51] showed that larval regurgitant increased production of ethylene and activity of two plant enzymes, peroxidase and polyphenol oxidase. The larval regurgitant can override proteinase inhibitors produced by the plant to limit the growth of herbivores. Indeed, two studies showed that the regurgitant of larvae prevented these genes transcribing some proteinase inhibitors [52,53]. Another study on gene expression in tomato, Lycopersicon esculentum L., showed that CPB larval regurgitant, induced a lower expression of defense genes compared with that induced by larval regurgitant of Manduca sexta (L.) (Lepidoptera: Sphingidae) [54]. 
Figure 2. Potential deterrents for Colorado potato beetle, Leptinotarsa decemlineata, include glycoalkaloids and a derived aglycone. Abbreviations for sugar group: Rha: Rhamnose; Gal: Galactose; Glu: Glucose; Xyl: Xylose.
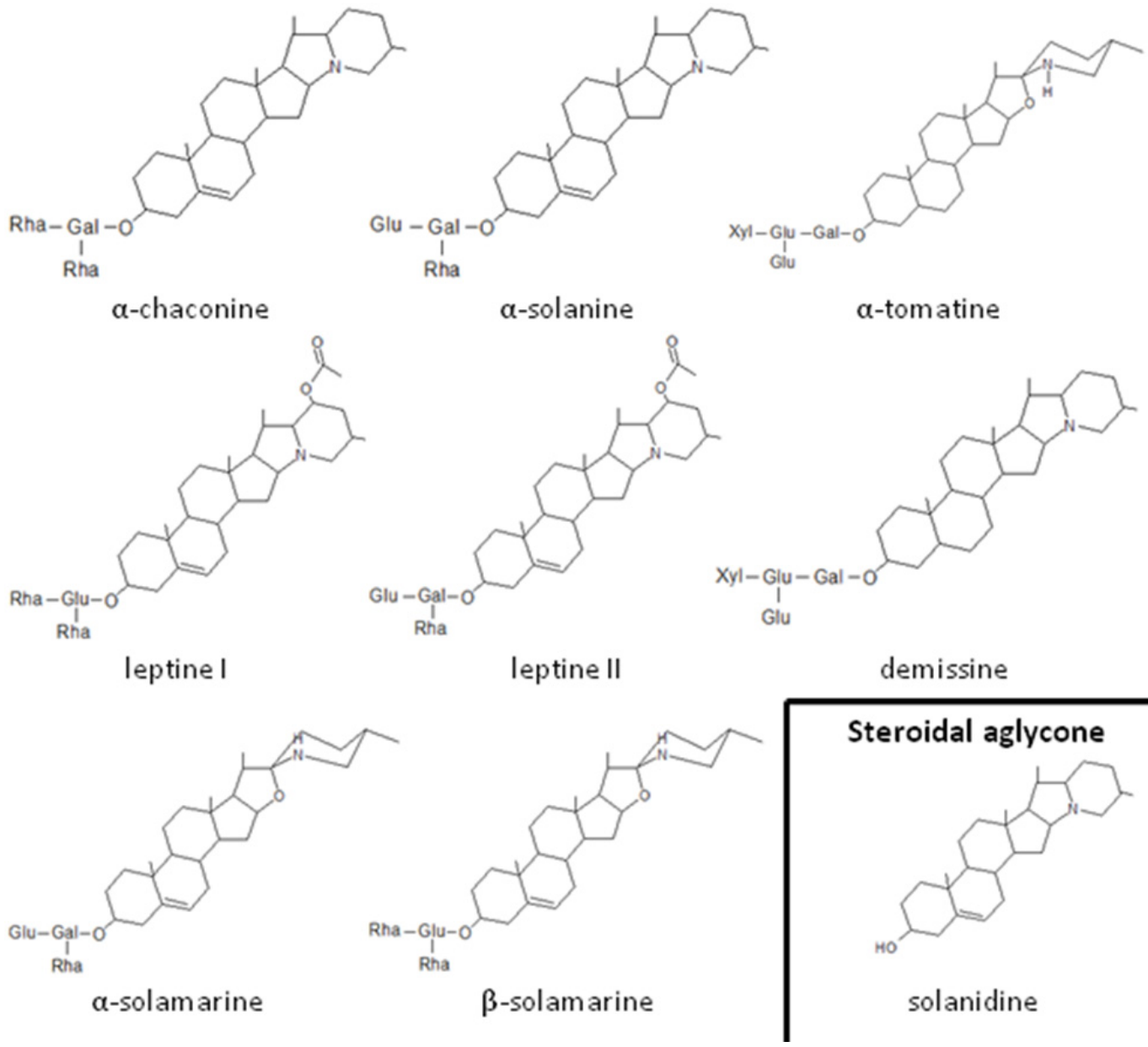

\subsection{Role of Plant Volatiles in CPB Orientation}

When CPB complete diapause and emerge from soil in spring, they quickly need to find host plants, using their olfactory system to locate a food source. The first observation on the attractive effect of volatile organic compounds (VOC) from potato was made by McIndoo [55] using an olfactometer test. In 1950, Chin also found that larvae were attracted by potato VOCs but at very short distances $(<5 \mathrm{~mm})$ in an assay without airflow [56]. In a wind tunnel, De Wilde et al. [57] showed that CPB adults were: (1) attracted to odors released by potential host-plants (potato, tomato, bittersweet, black nightshade and celery), (2) indifferent to alder, and (3) repelled by grass and dandelion. The attraction by potatoes disappeared with excision of the fourth antennal segment [57]. In another study, Visser and Nielsen [58] showed that CPB were attracted to solanaceous plants and supposed that after contact with the host plant, other mechanisms were involved in final acceptance. Starved males and females were attracted to undamaged potato plants in a wind tunnel [59]. Attraction of CPB toward potato plants was stronger with plants aged from four to eight weeks than with young potato plants [59]. Further, Thiery and Visser [60] showed that hunger was also important. In experiments using a servosphere, fed females exhibited less direct paths to potato VOCs, a decrease of the average speed, and more stops compared to starved females which showed a more distinct attraction to potato VOCs. 
In 1979, Visser et al. characterized several VOCs called green leaf volatiles (GLVs) from potato with a successive vacuum steam distillation, freeze concentration, and extraction. (E)-2-hexen-1-ol, 1-hexanol, (Z)-3-hexen-1-ol, (E)-2-hexenal, and linalool were identified as main components of potato odor [61]. Visser [62] used electroantennograms (EAGs) to show that olfactory receptors of CPB adults responded to VOCs including (E)-2-hexen-1-ol, (Z)-3-hexen-1-ol, 1-hexanol, $(E)$-2-hexenal, hexanal and (Z)-3-hexenyl-acetate, i.e. GLVs, and to their isomers such as (E)-3-hexen-1-ol and (Z)-2hexen-1-ol (Figure 3). Dickens [63] confirmed the EAG results of Visser [62] and demonstrated the importance of sexual maturity for the recognition and attraction of the plant VOCs. The sensitivity of CPB antennae to potato VOCs increased with the number of post emergence days and sexual maturation. Maximal antennal sensitivity was recorded at 6-8 days males and 12-14 days females [63]. VOCs were classified into five groups based on the development and magnitude of the EAGs they elicited: (1) chemicals with a strong response and a weak variability during sexual maturation such as (Z)-3-hexen-1-ol and (E)-2-hexen-1-ol; (2) chemicals with an intermediate response and slightly increasing response with maturity such as methyl salicylate, nonanal, and (Z)-3-hexenyl butyrate; (3) chemicals with a low response and a little variation with maturation, including indole, $( \pm$ )-linalool, and decanal; (4) chemicals with a weak response and slightly increasing reaction during the maturation such as $\beta$-caryophyllene and $\beta$-selinene; (5) chemicals with a weak response and a decreasing activity with maturation, including 1,8-cineole, $(R)-(+)$-limonene, $(S)-(-)$-limonene, myrcene, $(1 R)-(+)$-a-pinene, $(1 S)-(-)$-a-pinene, a-humulene, and $(+)$-longifolene. Mitchell and McCashin [64] showed that CPB may also taste GLVs. They found that nerve cells housed within the galeal sensilla of both adult and larval CPB responded to primary alcohols (hexanol and heptanol) and other components found among the GLV mixture such as the monounsaturated $(Z)$ - and $(E)$-isomers of hexen-1-ol and the six-carbon aldehyde analog, $(E)$-2-hexenal.

Figure 3. Green leaf volatiles and their isomers from potato as potential chemical signals for the Colorado potato beetle, Leptinotarsa decemlineata.

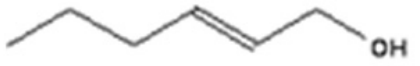

(E)-2-hexen-1-ol

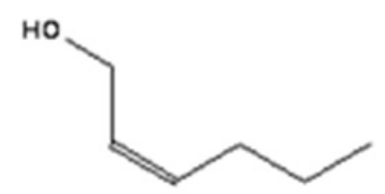

(Z)-2-hexen-1-ol

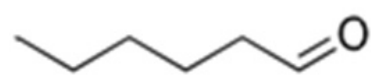

hexanal<smiles>CC/C=C/CCO</smiles>

(E)-3-hexen-1-ol

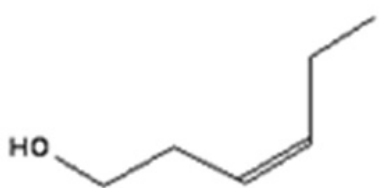

(Z)-3-hexen-1-ol

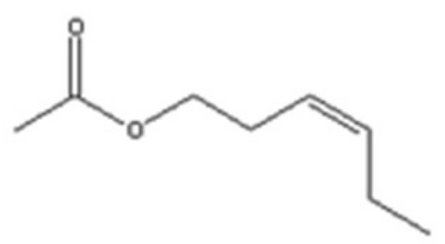

(Z)-3-hexenyl-acetate

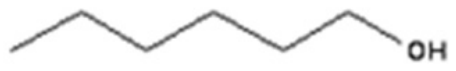

1-hexanol

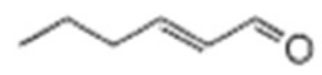

(E)-2-hexenal

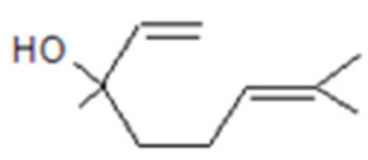

linalool 
GLVs are found in the headspace of most plant species and the fact that beetles distinguish potatoes from other plants is thought to be due to their ability to perceive the proper ratio of GLVs corresponding to potatoes [65]. Indeed, GLVs identified as originating from potato were tested individually and CPB females showed no attractive effect [61]. When potato GLVs were added, one by one, to the original odor cocktail from potato, no attraction was found, demonstrating that the whole cocktail of GLV in a very specific ratio, attract CPB [65]. Using an open air Y-olfactometer, CPB discriminated between two plants on the basis of their VOCs [66]. In this study, CPB preferentially chose potato versus tomato and eggplant, and preferred volatiles of the eggplant over the tomato. In field studies, when potatoes were intercropped or surrounded by other plants, the positive anemotaxis disappears because CPB do not perceive the potato odor blend alone. This change in the ratio of individual volatiles within the odorous blend disrupts orientation of CPB [67-69], a point that will be discussed further in a context of integrated pest management (IPM).

Wounded potato plants have different emissions of VOCs compared to healthy plants, and changes depend on the nature of the damage: mechanical damage, molecules eliciting defense mechanisms, or CPB-infested plants. Whatever the origin of damage, CPB adults are attracted [70-72]. Bolter et al. [70] confirmed the results of Visser [59] that old plants were attractive to CPB females while young plants did not attract beetles. When plants were wounded using carborundum powder, VOCs were released that induced positive anemotaxis [70]. Positive anemotaxis was observed when CPB larvae actively fed on foliage, but this behavior disappeared when CPB wounded potatoes were tested $50 \mathrm{~min}$ after a feeding period of $30 \mathrm{~min}$. When the feeding duration was longer, attraction was observed for a longer period of time. This study suggested that there are different volatiles inducing attraction. First, VOCs released directly from the wound site and later VOCs in response to herbivorous pests [70]. Similar results were found for damage caused by Spodoptera exigua (Hübner) (Lepidoptera: Noctuidae) larvae feeding on potato [70]. Potato plants injured by CPB larvae released an amount of VOCs seven to ten-fold higher than quantities released by healthy plants [70]. Anemotactic behavior of CPB was evaluated for VOCs released by plants that were: (1) damaged by insect feeding (CPB and cabbage looper, Trichoplusia ni (Hübner) (Lepidoptera: Noctuidae)), (2) chemically treated with either volicitin, a molecule isolated and identified from beet armyworm larval regurgitant that induces corn seedlings to emit volatiles [73] or methyl jasmonate, a compound that induces synthesis of proteinase inhibitors in plant leaves [74], (3) mechanically damaged [71,72]. Damage by CPB and cabbage looper larval feeding was mimicked by making an incision on the leaf and applying larval regurgitant to the wound. During the study by Schutz et al. [72], preference tests showed a greater attraction for: plants damaged and treated with CPB larval regurgitant > mechanically damaged plants $>$ undamaged plants. Another study showed similar results and noted that plants damaged and treated with larval regurgitant (CPB and cabbage looper) or chemicals (volicitin or methyl jasmonate) were attractive for CPB females while undamaged plants were not attractive [71]. Moreover, Schutz Schutz et al. [72] demonstrated attraction by $\beta$-caryophyllene over a short distance while 2-phenylethanol was attractive at a long distance.

CPB larvae (2nd and 4th instar) are also attracted by the odors from healthy and injured potato plants, without showing any preference for one or the other [75]. A three component blend comprising $( \pm$ )-linalool, methyl salicylate and (Z)-3-hexenyl acetate attracted both larval and adult CPB, the latter being attracted to lower concentrations of this chemical blend [75]. Hammock et al. [76] found similar 
results for CPB larval perception of potato VOCs and noted that larvae reduce their speed in the presence of VOCs, perhaps indicative of the proximity of food resources.

For additional descriptions of setups used in behavioral assays, we recommend the chapter of Hare [77] in "Methods in Chemical Ecology, Vol. 2".

\section{Intraspecific Communication in CPB}

\subsection{Sexual Recognition and Sex Pheromone}

In 1969, De Wilde et al. hypothesized a sex pheromone in CPB mating behavior [57]. Males were attracted by excised elytra of females; this attraction disappeared when elytra were extracted for $2 \mathrm{~h}$ with pentane in a Soxhlet apparatus [78]. This pheromone is likely to act after contact between partners. Jermy and Butt [79] demonstrated that a glass rod, covered by an extract of female elytra, stimulated males to copulate with the rod.

In a greenhouse assay, males moved from a potato plant toward another potato plant $50 \mathrm{~cm}$ distant downwind that was infested by females [80]. While this study suggested that a female sex pheromone attracted males over a short distance, one must be cautious when speaking about "sex pheromone" because a chemical has never been identified and the percentage of males attracted by females was relatively low [80].

Dubis et al. [81] identified cuticular hydrocarbons of CPB and found the same hydrocarbons in both sexes but with quantitative differences. However, long-chained hydrocarbons were present in higher proportion in females than in males. Physical contact between two individuals of opposite sex also influences foraging behavior toward host plants. After a single contact with another beetle of the opposite sex, CPB remained attracted to potato VOCs for 24 hours, but during the second day, this attraction disappeared. Attraction to VOCs emitted by potato reappeared only after 72 hours. This should be considered as an adaptation to lower attraction for host plant while enhancing reproduction success as suggested by Dickens who observed that during two days, beetles moved less and increases their chances to meet a sexual partner [82]. These studies demonstrated the importance of contact between partners but did not demonstrate the existence of long-range sex pheromone. These studies led some researchers to reconsider the existence of a volatile sex pheromone and to explore other possibilities of long-range pheromones.

\subsection{Aggregation Pheromone and Aggregation Behavior}

While several studies were directed to the characterization of a potential female-produced sex pheromone (see above), Dickens et al. [83] announced the discovery of an aggregation pheromone produced by males. Using GC-EAD (gas chromatography coupled with an electroantennographic detector) for analysis of aeration extracts of CPB males, active components were identified which

elicited responses from olfactory receptors of both males and females. Among these chemicals, a single molecule was only found in volatiles of plants being fed on by male beetles. As only small quantities of the unknown compound were released, it was reasoned that males must regulate release through a feedback loop involving olfactory receptors on the antennae. When the antennae were excised, quantities of the unknown compound increased 40-fold. Topical application of juvenile 
hormone III (JH III) also stimulated pheromone release to a lesser extent. However, the combination of antennectomy and JH III treatment allowed a 200-fold increase, thus facilitating identification of the compound as (S)-3,7-dimethyl-2-oxo-oct-6-ene-1,3-diol, named (S)-CPB I (Figure 4) [83]. The biological effect of $(S)$-CPB I was first evaluated in a Y-olfactometer on male and female CPB, both of which were highly attracted. The $(R)$ enantiomer and the racemic mixture were not attractive [83]. CPB larvae also seem capable of perceiving the aggregation pheromone produced by adults, but further studies are needed to characterize larval behavior [76]. This aggregation pheromone should be useful in IPM programs as a key component of a potential attracticide (see later).

Figure 4. Male-produced aggregation pheromone for Colorado potato beetle, Leptinotarsa decemlineata: (S)-3,7-dimethyl-2-oxo-oct-6-ene-1,3-diol or (S)-CPB I.

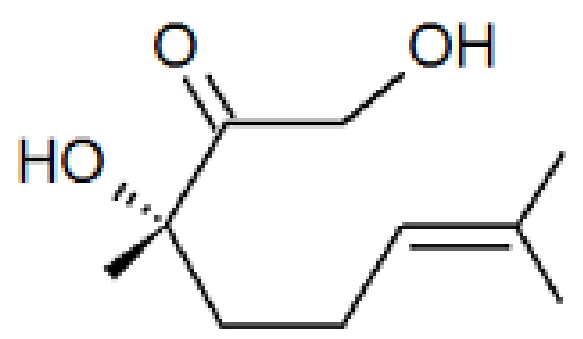

\section{Interspecific Interactions}

\subsection{Defensive Chemicals}

CPB hemolymph contains a protein called leptinotarsin which is highly toxic when injected directly in insects or vertebrates. However leptinotarsin was found to be less toxic when ingested [84]. In mammals, this protein instantaneously blocks heart muscle cells [84-86]. Leptinotarsin also limits reproduction of the pathogenic nematode, Heterorhabditis marelatus Liu and Berry, in CPB [87].

When disturbed, adult CPB eject a secretion through defensive glands located on the pronotum and the elytra. The major chemical component of the secretion has been identified as $\gamma$-L-glutamyl-L-2amino-3(Z), 5-hexadienoic acid [88]. Preliminary experiments suggested that this molecule is toxic for Myrmica rubra (L.) (Hymenoptera: Formicidae) and deterrent for chickens [88,89].

\subsection{Volatile Perception by Predators}

Dickens [90] analyzed GC-EAD responses of a generalist and a specialist CPB predator, respectively, Podisus maculiventris (Say) (Hemiptera: Pentatomidae) and Perillus bioculatus (Fabr.) (Hemiptera: Pentatomidae), to constitutive odors and systemic volatiles elicited by CPB feeding. GCEAD tests showed that, unlike CPB that detect easily GLVs, predators were more sensitive to volatile molecules induced by the systemic reaction of the plant injured by CPB larvae. Other studies on $P$. bioculatus showed the attractant effect of plant volatiles from a CPB infested plant [91-93]. CPB damage of plants caused a systemic reaction inducing production of VOCs that attracted third and fifth instars of $P$. maculiventris [94]. 


\subsection{Interactions between Different Pest Species}

The fact that a potato field is already attacked by another herbivore than CPB may influence the distribution of CPB. Bolter et al. [70] first demonstrated attraction of CPB adults to potatoes damaged by heterospecific herbivores, e.g., S. exigua larvae. Field cage tests with high densities of leafhoppers affected CPB as: (1) fewer egg masses on the potato foliage were observed, (2) larval development was longer with fewer surviving and (3) freshly emerged adults weighed less [95]. While this competition between the herbivores could be used by farmers to limit colonization by $\mathrm{CPB}$, one must ensure that leafhopper damage does not involve an important yield loss. Furthermore, the idea of placing other pests competitive with $\mathrm{CPB}$ on potatoes remains unrealistic as farmers would be unlikely to accept such an approach.

Gosset et al. [96] demonstrated that volatiles emitted by injured potato depended on whether the herbivores were piercing-sucking or chewing type feeders. Despite apparently lesser injuries inflicted by the aphid, Myzus persicae (Sulzer) (Homoptera: Aphididae), a greater number of volatiles were released, perhaps due to pathogen infection. Aphids were also unaffected by preliminary CPB wounding, suggesting that the presence of $\mathrm{CPB}$ does not influence the colonization behavior of Macrosiphum euphorbiae (Thomas) (Homoptera: Aphididae) [97].

\section{Semiochemical-Based IPM Strategies}

Recent discoveries have enhanced knowledge of chemical communication in CPB and highlight the potential of semiochemicals as a component of future integrated management strategies. However, the chemical ecology of CPB is not yet completely understood and this incomplete knowledge makes semiochemical-based approaches inefficient when compared to traditional insecticide treatments. However, alternative strategies have potential in the control of CPB populations and include: (1) disorientation of CPB adults by masking potato VOCs with intercropping cultures; (2) use of synthetic mixtures of volatiles and/or aggregation pheromone to trap beetles; (3) antifeedant sprays on potatoes; (4) increase, with genetic manipulations, the natural capacity of the plant to recognize the presence of $\mathrm{CPB}$ through chemical signals, thus triggering defense mechanisms. These tools are summarized in Table 2.

\subsection{Disorientation of CPB Adults with Masking Odors}

Intercropping represents an efficient method to repel and/or confuse CPB foraging for host plants. Among the 13 identified compounds from tansy oil, five were repellents ( $\alpha$ - and $\gamma$-terpinene, $\alpha, \beta$ thujone, dihydrocarvone and carvone) and one compound ( $\alpha$-pinene) was an attractant [98]. When tansy was used as an intercrop in potato fields, a $60 \%-100 \%$ decrease in the number of beetles present in the fields was observed [99]. Two other studies have shown that potato VOCs mixed with VOCs from tomato or cabbage, disrupted the searching behavior of CPB females for host plants $[68,69]$.

These initial results demonstrate the exciting potential of intercropping and support preliminary laboratory studies by Visser and Ave [65] that suggested that host orientation could be disrupted by modification of the ratio VOCs. Moreover, few intercropping models were studied and further investigations should be considered with other plant species. 
Table 2. Different approaches suggested to control the Colorado potato beetle.

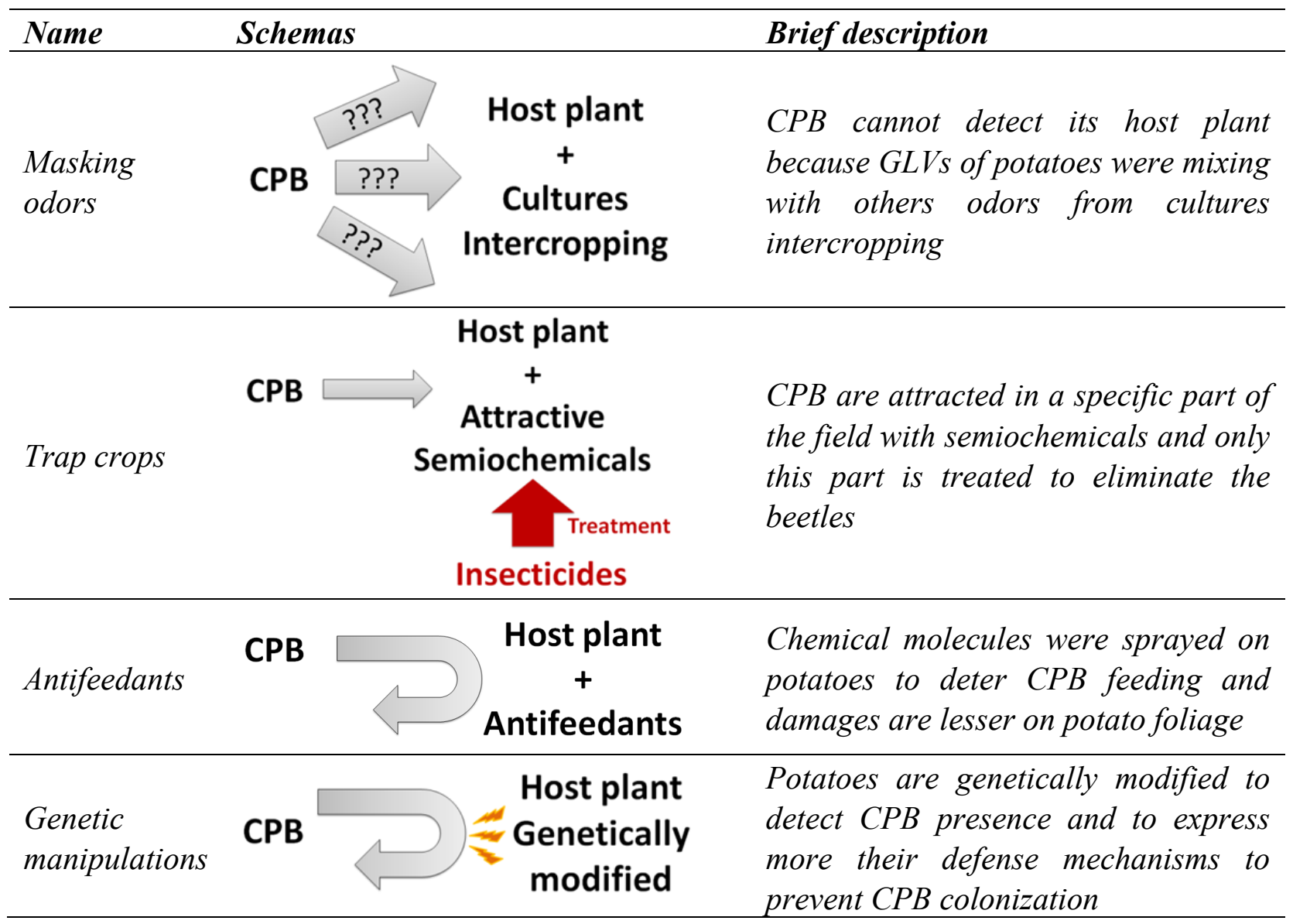

\subsection{Use of Attractants and Aggregation Pheromone}

The use of semiochemical attractants to improve insecticide treatments should be considered as an innovative approach of CPB management. Chewing insects are indeed more sensitive to VOCs released by their host plants because the damage they induce in plant tissues increases the release of these compounds [100]. The difficulty consists in finding a cocktail of natural odors within which the quantitative proportion of each compound is as close as possible to that of the naturally emitted blend [65]. The challenge therefore consists in finding the appropriate molecules and their ratio, instead of trying to include as many compounds in the mixture as possible [100].

The first synthetic blend to show potential in CPB management was comprised of (E)-2-hexen-1-ol, (Z)-3-hexen-1-ol, nonanal, $( \pm$ )-linalool and methyl salicylate prepared in paraffin oil [90]. This blend, placed in competition with pure air attracted CPB adults in behavioral assays with a "T" choice test in the laboratory. For better efficiency, the proportion of $(E)$-2-hexen-1-ol and (Z)-3-hexen-1-ol were 10-fold lower compared to the three other compounds [90]. Dickens [75] also reported a synthetic blend of three compounds, $(Z)$-3-hexenyl acetate, $( \pm$ )-linalool and methyl salicylate, which attracted second and fourth larval instars. This blend attracted CPB adults with a 10-fold lower concentration for females and 100-fold lower for males. Yet, an earlier study of [101] could not show attraction of females with this last blend. This attractive blend for all stages of CPB has a very interesting potential for creating attracticides in the field [75]. 
The synthetic blend made of (Z)-3-hexenyl acetate, $( \pm)$-linalool and methyl salicylate, firstly reported in Dickens study [75] was evaluated in a greenhouse where it attracted newly emerged and 5day-old adults when released at a rate of $57 \mu \mathrm{g} / \mathrm{h}$ [102]. However, habituation was observed in the beetles that were exposed more than 12 hours to this mixture. Initial field tests confirmed the effect of the attractant blend and its usefulness for semiochemical-based control [103]. Pitfall traps baited with the attractant captured a greater number of CPB in potato fields. Moreover, fewer egg masses and larvae were observed in neighboring untreated crops. The use of trap crops with the attractive blend allowed a decrease of $44 \%$ insecticides for similar yields to the conventional method [103].

The first field experiments with the aggregation pheromone, $(S)$-CPB I, were performed by Kuhar et al. [104]. They placed pitfalls traps baited with the aggregation pheromone in a 0.5-ha land section cultivated for a good soil uniformity and wherein they released $400 \mathrm{CPB}$ adults in the centre. More than 5-fold numbers of $\mathrm{CPB}$ adults were captured in traps baited with septa releasing the pheromone than in control traps. This significant difference in treatment numbers disappeared after 5 days presumably due to evaporation loss or degradation of the pheromone. In the second part of their study, they showed that fewer CPB eggs and larvae were present in plots bordered with pheromonetreated plots than in field plots bordered with untreated rows [104]. While these preliminary results offer promise for use of the pheromone in the field, more research is needed before practical applications may be available.

In laboratory tests with an vertical Y-olfactometer, CPB adults were confronted with a cocktail of three volatiles, $(Z)$-3-hexenyl acetate, $( \pm)$-linalool and methyl salicylate, opposite to the aggregation pheromone [105]. Half of the tested CPB adults chose the aggregation pheromone side of the olfactometer and the other half chose the side connected to the plant volatiles. This indicates that CPB adults were unable to choose between plant VOCs blend and their aggregation pheromone in this vertical bioassay. However, in mowed field assays, the aggregation pheromone coupled with the blend of three odors attracted significantly more CPB adults in comparison with the plant odors blend alone [105].

Another study in fields was made with the synthetic blend of three plant odors [(Z)-3-hexenyl acetate, $( \pm)$-linalool and methyl salicylate] [106]. The synthetic blend was coupled with a pyrethroid insecticide at different concentrations. A decrease in first and second instar CPB was observed with an application of $2 \%$ or $6 \%$ active ingredient permethrin coupled with the odorous blend but this method did not significantly decrease older larval stages because the insecticides were more efficacious on young larval stages [107]. However, the use of this attracticide showed the same control efficiency as the commercial insecticide while using 92\% less insecticide by active ingredient [106]. As many CPB populations in the U.S. have developed resistance to permethrin [108], the authors suggested imidacloprid as a replacement [106].

When considering use of chemical signals for manipulation of the behavior of CPB or other insects, it is important to understand that behavior of insects is a result of integration of multimodal signals in the environment of which olfaction represents only one of the input channels. For example, CPB walking on a servosphere orient to the aggregation pheromone in darkness [109]. However, in the presence of yellow light, a known attractant for CPB, orientation to the pheromone is abolished [110]. Thus, better understanding the complexities of the behavior of CPB and other insects to multimodal signals will enhance design and deployment of management strategies employing naturally-occurring chemical signals. 
The main difficulty with semiochemicals is ensuring a controlled release during a long period. This depends of the active molecule and its release rate kinetic. The knowledge of these molecules is thus essential. Other parameters such as UV light, oxygen, pluviometry and temperature could also alter semiochemicals. Therefore, the choice of the dispenser is also important to control the release and to prevent molecule degradation [111].

\subsection{Antifeedants}

Antifeedants to deter CPB adults and larvae include a wide variety of chemicals. The first chemical deterrents were identified by Hsiao and Fraenkel [112]. Other studies identified a multitude of additional antifeedants including: (1) constituents of some plants from the sagebrush community [113], (2) hydroxides which also act as fungicides [114], alcohol extracts of the leaves and bark of Quercus alba L. [115], (3) limonin [116], (4) a-mangostin [117], (5) sesquiterpenes [118], (6) terpenoid lactones [119], and (7) extracts from various plants [120,121] including wild species of potatoes $[122,123]$. Such molecules and blends of chemicals not only reduce feeding but also may deter oviposition by females as shown for citrus limonoids [124,125]. A phagorepellent effect was also found for leaf surface molecules specific to commercial varieties of $S$. tuberosum. However, the deterrent effect was observed when concentration of these molecules was 10-fold higher than in natural leaves [126]. One should be cautious when discussing antifeedants as physical properties of the plant (e.g., trichomes) and systemic modification of the plant due to the application of an external molecule may also play a deterrent role, an indirect antifeedant effect [127].

Other field assays were conducted in Hungary by Szentesi [128] in which crops were treated with a $2 \%$ Bordeaux mixture during two consecutive weeks. This treatment resulted in significantly more eggs laid on the treated potatoes. The unequal distribution of eggs may have been caused by: (1) a decrease of foliage surface, (2) the presence of different larval instars or (3) the presence of larval and adult feces on unsprayed potatoes, thus highlighting the potential of field areas treated as egg traps [128]. In another study, fields treated regularly with fungicides, triphenyltin hydroxyde (TPTH) or copper hydroxyde $\left(\mathrm{Cu}[\mathrm{OH}]_{2}\right)$, had fewer $\mathrm{CPB}$ larvae, consistent with these fungicides acting as deterrents. The authors suggested a regular application of TPTH to reduce the use of insecticides and decrease cost [129].

A neem-seed extract showed good efficiency to control CPB in fields but the magnitude of the effects depended on the dominant CPB life stage present when the application was made [130]. Yields were in some cases commercially acceptable, thus suggesting that neem seed extract applied in the potato growing season may control young larvae without insecticides. In 2006, Moreau et al. [131] showed that application of $2 \%$ neem reduced CPB densities and defoliation resulting in increased tuber yields. Azadirachtin is the main active molecule from neem extract and a field evaluation with this natural antifeedant showed satisfactory results for reduction of plant damages [132].

Fields tests on the deterrent effect of citrus limonoids were made during three seasons in Maine. Colonizing CPB adults were fewer in limonoid treated plots, with a decrease in egg masses and smaller numbers of larvae [133]. These results were opposite with those of Szentesi [128] who showed that oviposition increased on potato plants treated with an antifeedant, $2 \%$ Bordeaux mixture. Murray et al. [134] showed that two applications of a high concentration $(10.8 \mathrm{~kg} / \mathrm{ha})$ and three 
applications at a lower dose $(3,6 \mathrm{~kg} / \mathrm{ha})$ of citrus limonoids were sufficient to maintain the rate of defoliation below $60 \%$, allowing acceptable yields. This study seemed to confirm the potential of limonoids for the management of young larvae at the beginning of the potato growing season [125].

Despite decades of study, the commercialization of antifeedants has been generally unsuccessful because: (1) they were considered as synthetic insecticides, (2) the life span of an antifeedant may vary depending on weather conditions, (3) they may take a long time before acting and (4) they do not always kill or deter target insects [133].

\subsection{Genetic Manipulations}

Recently there has been interest in genetic manipulation of potato to enhance expression of deterrent compounds. Hybrid assays were conducted with $S$. tuberosum and wild potato species to incorporate the gene expressing leptine and additional glycoalkaloids, to create commercial varieties having enhanced tuber yields and repellent activity [135,136]. Another possibility of genetically modified (GM) potatoes would take advantage of their hypersensitivity to chemical molecules associated with the presence of CPB eggs. In 1972, Wegorek \& Dubniak [137] observed necrotic areas near oviposition sites on potato leaves in Polish fields. Since no microorganisms were detected near the plant necrosis, the authors supposed that the necrosis was due to female substances secreted during oviposition. Balbyshev \& Lorenzen [138] observed a hybrid potato species with a hypersensitive response to egg deposition; a necrosis around eggs followed by the detachment of this part of the leaf. As neither bacteria nor microorganisms were found, they supposed a chemical associated with eggs was responsible for the defoliation. The consequence of this resistance mechanism was that egg masses fell on the soil, thus increasing predation by soil-dwelling predators such as carabids [138].

\section{Conclusions}

Today, research is still being conducted to better understand CPB biology in an effort to devise new control techniques. Toxic chemical treatments have been the best method to control CPB despite continual development of resistance. Now because of the inevitable decline of effective insecticide treatments, research should focus even more on the development of new control methods and approaches. Some methods such as cultivating GM plants are not seen positively by consumers, and farmers have abandoned them due to a lack of buyers [139]. Among the various alternative control techniques, chemical signals seem to be promising, especially when coupled with the use of natural predators and targeted pesticide treatments. Thus, it is necessary to continue to explore alternative control methods using semiochemicals and important to better understand behaviors generated by these semiochemicals.

The genetic variability between CPB populations, which seems to be greater for U.S. populations than for those in Europe [140], is also important to consider. Effectively, CPB have shown metabolic adaptations for: (1) insecticide resistance [10,141], (2) range expansion [142], and (3) different Solanaceous hosts $[33,143,144]$. One study on two different CPB populations showed a difference of intensity in perception of VOCs between Utah and Wageningen populations [145]. Differences in perception of VOCs and perhaps other chemical signals between CPB populations may be important for the development of semiochemical-based control strategies and merit more investigations. 


\section{Acknowledgements}

We thank the CURAGx for financial support granted to start Ludovic Sablon PhD thesis.

\section{References and Notes}

1. Casagrande, R.A. The Colorado potato beetle: 125 years of mismanagement. Bull. Entomol. Soc. Am. 1987, 33, 142-150.

2. Riley, C.V. Seven Annual Report on the Noxious, Beneficial, and Other Insect of the State of Missouri; Regan \& Carter: Jefferson City, MS, USA, 1875.

3. du Chatenet, G. Coléoptères Phytophages d'Europe : Chrysomelidae; N.A.P Editions: Verrières Le Buisson, France, 2002; Vol. 2, pp. 258.

4. Weber, D.C. Colorado beetle: Pest on the move. Pesticide Outlook 2003, 14, 256-259.

5. Hare, J.D. Impact of defoliation by the Colorado potato beetle on potato yields. J. Econ. Entomol. 1980, 73, 369-373.

6. Hare, J.D. Ecology and management of the Colorado potato beetle. Annu. Rev. Entomol. 1990, $35,81-100$.

7. Harcourt, D.G. Population dynamics of Leptinotarsa decemlineata (Say) in eastern Ontario. III. Major population processes. Can. Entomol. 1971, 103, 1049-1061.

8. Ferro, D.N.; Logan, J.A.; Voss, R.H.; Elkinton, J.S. Colorado potato beetle (Coleoptera: Chrysomelidae) temperature-dependent growth and feeding rates. Environ. Entomol. 1985, 14, 343-348.

9. Walgenbach, J.F.; Wyman, J.A. Colorado potato beetle (Coleoptera: Chrysomelidae) development in relation to temperature in Wisconsin. Ann. Entomol. Soc. Am. 1984, 77, 604-609.

10. Alyokhin, A.; Baker, M.; Mota-Sanchez, D.; Dively, G.; Grafius, E. Colorado potato beetle resistance to insecticides. Am. J. Potato Res. 2008, 85, 395-413.

11. Alyokhin, A. Colorado potato beetle management on potatoes: Current challenges and future prospects. Fruit Vegetable Cereal Sci. Biotechnol. 2009, 3, 10-19.

12. Bishop, B.A.; Grafius, E.J. Insecticide resistance in the Colorado potato beetle. In Chrysomelidae Biology; Jolivet, P., Hsiao, T.H., Eds.; SBP Academic Publishing: Amsterdam, The Netherlands, 1996; Volume 1, pp. 355-377.

13. Clark, J.M.; Argentine, J.A. Biochemical mechanisms of insecticide resistance in the Colorado potato beetle. In Advances in Potato Pest Biology and Management; Zehnder, G.W., Powelson, M.L., Jansson, R.K., Raman, K.V., Eds.; APS Press: St. Paul, Minnesota, USA, 1994; pp. 294-308.

14. Weisz, R.; Smilowitz, Z.; Christ, B. Distance, rotation, and border crops affect Colorado potato beetle (Coleoptera, Chrysomelidae) colonization and population-density and early blight (Alternaria-solani) severity in rotated potato fields. J. Econ. Entomol. 1994, 87, 723-729.

15. Weber, D.C.; Ferro, D.N.; Buonaccorsi, J.; Hazzard, R.V. Disrupting spring colonization of Colorado potato beetle to nonrotated potato fields. Entomol. Exp. Appl. 1994, 73, 39-50. 
16. Coombs, J.J.; Douches, D.S.; Li, W.B.; Grafius, E.J.; Pett, W.L. Combining engineered (Btcry $3 \mathrm{~A}$ ) and natural resistance mechanisms in potato for control of Colorado potato beetle. J. Am. Soc. Hortic. Sci. 2002, 127, 62-68.

17. Grafius, E.J.; Douches, D.S. The present and future role of insect resistant, genetically modified potato cultivars in potato IPM. In Integration of Insect-Resistant GM Crops within IPM Programs; Romeis, J., Shelton, A.M., Kennedy, G.G., Eds.; Springer: New York, NY, USA, 2008; pp. 195-222.

18. Lashomb, J.H.; Ng, Y.S. Colonization by Colorado potato beetles, Leptinotarsa decemlineata (Say) (Coleoptera: Chrysomelidae), in rotated and nonrotated potato fields. Environ. Entomol. 1984, 13, 1352-1356.

19. Hoy, C.W.; Vaughn, T.T.; East, D.A. Increasing the effectiveness of spring trap crops for Leptinotarsa decemlineata. Entomol. Exp. Appl. 2000, 96, 193-204.

20. Zehnder, G.W.; Hough-Goldstein, J. Colorado potato beetle (Coleoptera: Chrysomelidae) population development and effects on yield of potatoes with and without straw mulch. J. Econ. Entomol. 1989, 83, 1982-1987.

21. Misener, G.C.; Boiteau, G.; McMillan, L.P. A plastic-lining trenching device for the control of Colorado potato beetle - beetle excluder. Am. Potato J. 1993, 70, 903-908.

22. Pelletier, Y.; McLeod, C.D.; Bernard, G. Description of sublethals injuries caused to the Colorado potato beetle (Coleoptera, Chrysomelidae) by propane flamer treatement. J. Econ. Entomol. 1995, 88, 1203-1205.

23. Boiteau, G.; Misener, G.C.; Singh, R.P.; Bernard, G. Evaluation of vacuum collector for insect pest-control in potato. Am. Potato J. 1992, 69, 157-166.

24. Hough-Goldstein, J.A.; Heimpel, G.E.; Bechmann, H.E.; Mason, C.E. Arthropod natural enemies of the Colorado potato beetle. Crop. Prot. 1993, 12, 324-334.

25. Ferro, D.N. Biological control of the Colorado potato beetle. In Advances in Potato Pest Biology and Management; Zehnder, G.W., Jansson, R.K., Powelson, M.L., Raman, K.V., Eds.; APS Press: St. Paul, MI, USA, 1994; pp. 357-375.

26. Berry, R.E.; Liu, J.; Reed, G. Comparison of endemic and exotic entomopathogenic nematode species for control of Colorado potato beetle (Coleoptera:Chrysomelidae). J. Econ. Entomol. 1997, 90, 1528-1533.

27. Ebrahimi, L.; Niknam, G.; Lewis, E.E. Lethal and sublethal effects of Iranian isolates of Steinernema feltiae and Heterorhabditis bacteriophora on the Colorado potato beetle, Leptinotarsa decemlineata. Biocontrol 2011, 56, 781-788.

28. Wraight, S.P.; Ramos, M.E. Application parameters affecting field efficacy of Beauveria bassiana foliar treatments against Colorado potato beetle Leptinotarsa decemlineata. Biol. Control 2002, 23, 164-178.

29. Perlak, F.J.; Stone, T.B.; Muskopf, Y.M.; Petersen, L.J.; Parker, G.B.; McPherson, S.A.; Wyman, J.; Love, S.; Reed, G.; Biever, D.; Fischhoff, D.A. Genetically improved potatoes protection from damage by Colorado potato beetles. Plant Mol. Biol. 1993, 22, 313-321.

30. Coombs, J.J.; Douches, D.S.; Li, W.B.; Grafius, E.J.; Pett, W.L. Field evaluation of natural, engineered, and combined resistance mechanisms in potato for control of colorado potato beetle. J. Am. Soc. Hortic. Sci. 2003, 128, 219-224. 
31. Zhu, F.; Xu, J.J.; Palli, R.; Ferguson, J.; Palli, S.R. Ingested RNA interference for managing the populations of the Colorado potato beetle, Leptinotarsa decemlineata. Pest Manag. Sci. 2011, 67, 175-182.

32. Hsiao, T.H.; Fraenkel, G. Selection and specificity of the Colorado potato beetle for solanaceous and nonsolanaceous plants. Ann. Entomol. Soc. Am. 1968, 61, 493-503.

33. Harrison, G.D. Host-plant discrimination and evolution of feeding preference in the Colorado potato beetle Leptinotarsa-decemlineata. Physiol. Entomol. 1987, 12, 407-415.

34. Hsiao, T.H.; Fraenkel, G. The influence of nutrient chemicals on the feeding behavior of the Colorado potato beetle, Leptinotarsa decemlineata (Coleoptera:Chrysomelidae). Ann. Entomol. Soc. Am. 1968, 61, 44-54.

35. Hsiao, T.H. Chemical basis of host selection and plant resistance in oligophagous insects. Entomol. Exp. Appl. 1969, 12, 777-788.

36. Szafranek, B.; Chrapkowska, K.; Waligora, D.; Palavinskas, R.; Banach, A.; Szafranek, J. Leaf surface sesquiterpene alcohols of the potato (Solanum tuberosum) and their influence on Colorado beetle (Leptinotarsa decemlineata Say) feeding. J. Agric. Food Chem. 2006, 54, 7729-7734.

37. Chen, Z.B.; Miller, A.R. Steroidal alkaloids in solanaceous vegetable crops. Horticultural Reviews 2001, 25, 171-196.

38. Herb, S.F.; Fitzpatrick, T.J.; Osman, S.F. Separation of potato glycoalkaloids by gas chromatography. J. Agric. Food Chem. 1975, 23, 520-523.

39. Flanders, K.L.; Hawkes, J.G.; Radcliffe, E.B.; Lauer, F.I. Insect resistance in potatoes - sources, evolutionary relantionships, morphological and chemical defenses, and ecogeographical associations. Euphytica 1992, 61, 83-111.

40. Tingey, W.M. Glycoalkaloids as pest resistance factors. Am. Potato J. 1984, 61, 157-167.

41. Sinden, S.L.; Sanford, L.L.; Cantelo, W.W.; Deahl, K.L. Leptine glycoalkaloids and resistance to the Colorado potato beetle (Coleoptera: Chrysomelidae) in Solanum chacoense. Environ. Entomol. 1986, 15, 1057-1062.

42. Sinden, S.L.; Sanford, L.L.; Cantelo, W.W.; Deahl, K.L. Bioassays of segregating plants - a strategy for studying chemical defenses. J. Chem. Ecol. 1988, 14, 1941-1950.

43. Yencho, G.C.; Kowalski, S.P.; Kennedy, G.G.; Sanford, L.L. Segregation of leptine glycoalkaloids and resistance to Colorado potato beetle (Leptinotarsa decemlineata (Say)) in F2 Solanum tuberosum (4x) x S-chacoense (4x) potato progenies. Am. J. Potato Res. 2000, 77, 167-178.

44. Hollister, B.; Dickens, J.C.; Perez, F.; Deahl, K.L. Differential neurosensory responses of adult Colorado potato beetle, Leptinotarsa decemlineata, to glycoalkaloids. J. Chem. Ecol. 2001, 27, $1105-1118$.

45. Mitchell, B.K.; Harrison, G.D. Characterization of galeal chemosensilla in the adult Colorado beetle, Leptinotarsa decemlineata. Physiol. Entomol. 1984, 9, 49-56.

46. Mitchell, B.K. Interactions of alkaloids with galeal chemosensory cells of Colorado potato beetle. J. Chem. Ecol. 1987, 13, 2009-2022.

47. Hare, J.D. Growth of Leptinotarsa-decemlineata larvae in response to simultaneous variation in protein and glycoalkaloid concentration. J. Chem. Ecol. 1987, 13, 39-46. 
48. Kowalski, S.P.; Domek, J.M.; Deahl, K.L.; Sanford, L.L. Performance of Colorado potato beetle larvae, Leptinotarsa decemlineata (Say), reared on synthetic diets supplemented with Solanum glycoalkaloids. Am. J. Potato Res. 1999, 76, 305-312.

49. Lyytinen, A.; Lindstrom, L.; Mappes, J.; Julkunen-Tiitto, R.; Fasulati, S.R.; Tiilikkala, K. Variability in host plant chemistry: behavioural responses and life-history parameters of the Colorado potato beetle (Leptinotarsa decemlineata). Chemoecology 2007, 17, 51-56.

50. Armer, C.A. Colorado potato beetle toxins revisited: Evidence the beetle does not sequester host plant glycoalkaloids. J. Chem. Ecol. 2004, 30, 883-888.

51. Kruzmane, D.; Jankevica, L.; Ievinsh, G. Effect of regurgitant from Leptinotarsa decemlineata on wound responses in Solanum tuberosum and Phaseolus vulgaris. Physiol. Plant. 2002, 115, $577-584$.

52. Lawrence, S.D.; Novak, N.G.; Blackburn, M.B. Inhibition of proteinase inhibitor transcripts by Leptinotarsa decemlineata regurgitant in Solanum lycopersicum. J. Chem. Ecol. 2007, 33, 1041-1048.

53. Lawrence, S.D.; Novak, N.G.; Ju, C.J.T.; Cooke, J.E.K. Potato, Solanum tuberosum, defense against colorado potato beetle, Leptinotarsa decemlineata (Say): Microarray gene expression profiling of potato by colorado potato beetle regurgitant treatment of wounded leaves. J. Chem. Ecol. 2008, 34, 1013-1025.

54. Chung, S.H.; Felton, G.W. Specificity of induced resistance in tomato against specialist lepidopteran and coleopteran species. J. Chem. Ecol. 2011, 37, 378-386.

55. McIndoo, N.E. An insect olfactometer. J. Econ. Entomol. 1926, 19, 545-571.

56. Chin, C.T. Studies on the physiological relation between the larvae of Leptinotarsa decemlineata Say and some solanaceous plants. Eur. J. Plant Pathol. 1950, 56, 1-88.

57. De Wilde, J.; Hille Ris Lambers-Suverkropp, K.; Van Tol, A. Responses to air flow and airborne plant odour in the Colorado beetle. Neth. J. Plant Pathol. 1969, 75, 53-57.

58. Visser, J.H.; Nielsen, J.K. Specificity in the olfactory orientation of the Colorado beetle, Leptinotarsa decemlineata. Entomol. Exp. Appl. 1977, 21, 14-22.

59. Visser, J.H. The design of a low-speed wind tunnel as an instrument for the study of olfactory orientation in the Colorado beetle (Leptinotarsa decemlineata). Entomol. Exp. Appl. 1976, 20, $275-288$.

60. Thiery, D.; Visser, J.H. Satiation effects on olfactory orientations patterns of Colorado potato beetle females. Comptes Rendus Acad. Sci. Ser. III-Sci. Vie-Life Sci. 1995, 318, 105-111.

61. Visser, J.H.; Straten, S.V.; Maarse, H. Isolation and identification of volatiles in the foliage of potato, Solanum tuberosum, a host plant of the Colorado beetle, Leptinotarsa decemlineata. J. Chem. Ecol. 1979, 5, 13-25.

62. Visser, J.H. Electroantennogram responses of the Colorado beetle, Leptinotarsa decemlineata, to plant volatiles. Entomol. Exp. Appl. 1979, 25, 86-97.

63. Dickens, J.C. Sexual maturation and temporal variation of neural responses in adult Colorado potato beetles to volatiles emitted by potato plants. J. Chem. Ecol. 2000, 26, 1265-1279.

64. Mitchell, B.K.; McCashin, B.G. Tasting green leaf volatiles by larvae and adults of Colorado potato beetle, Leptinotarsa-decemlineata. J. Chem. Ecol. 1994, 20, 753-769. 
65. Visser, J.H.; Ave, D.A. General green leaf volatiles in the olfactory orientation of the Colorado beetle, Leptinotarsa decemlineata. Entomol. Exp. Appl. 1978, 24, 738-749.

66. Hitchner, E.M.; Kuhar, T.P.; Dickens, J.C.; Youngman, R.R.; Schultz, P.B.; Pfeiffer, D.G. Host plant choice experiments of Colorado potato beetle (Coleoptera : Chrysomelidae) in Virginia. $J$. Econ. Entomol. 2008, 101, 859-865.

67. Jermy, T.; Szentesi, A.; Horvath, J. Host plant finding in phytophagous insects - the case of the Colorado potato beetle. Entomol. Exp. Appl. 1988, 49, 83-98.

68. Thiery, D.; Visser, J.H. Masking of host plant odour in the olfactory orientation of the Colorado potato beetle. Entomol. Exp. Appl. 1986, 41, 165-172.

69. Thiery, D.; Visser, J.H. Misleading the Colorado potato beetle with an odor blend. J. Chem. Ecol. 1987, 13, 1139-1146.

70. Bolter, C.J.; Dicke, M.; vanLoon, J.J.A.; Visser, J.H.; Posthumus, M.A. Attraction of Colorado potato beetle to herbivore-damaged plants during herbivory and after its termination. J. Chem. Ecol. 1997, 23, 1003-1023.

71. Landolt, P.J.; Tumlinson, J.H.; Alborn, D.H. Attraction of Colorado potato beetle (Coleoptera : Chrysomelidae) to damaged and chemically induced potato plants. Environ. Entomol. 1999, 28, 973-978.

72. Schutz, S.; Weissbecker, B.; Klein, A.; Hummel, H.E. Host plant selection of the Colorado potato beetle as influenced by damage induced volatiles of the potato plant. Naturwissenschaften 1997, 84, 212-217.

73. Alborn, H.T.; Turlings, T.C.J.; Jones, T.H.; Stenhagen, G.; Loughrin, J.H.; Tumlinson, J.H. An elicitor of plant volatiles from beet armyworm oral secretion. Science 1997, 276, 945-949.

74. Farmer, E.E.; Ryan, C.A. Interplant communication - airborne methyl jasmonate induces synthesis of proteinase-inhibitors in plant-leaves. Proc. Natl. Acad. Sci. USA 1990, 87, 7713-7716.

75. Dickens, J.C. Behavioural responses of larvae of Colorado potato beetle, Leptinotarsa decemlineata (Coleoptera: Chrysomelidae), to host plant volatile blends attractive to adults. Agric. For. Entomol. 2002, 4, 309-314.

76. Hammock, J.A.; Vinyard, B.; Dickens, J.C. Response to host plant odors and aggregation pheromone by larvae of the Colorado potato beetle on a servosphere. Arthropod-Plant Interact. 2007, 1, 27-35.

77. Hare, J.D. Bioassay methods with terrestrial invertebrates. In Methods in Chemical Ecology; Haynes, K.F., Millar, J.G., Eds.; Kluwer Academic Publishers: Dordrecht, The Netherlands, 1998; Volume 2, pp. 212-270.

78. Levinson, H.Z.; Levinson, A.R.; Jen, T.L. Sex recognition by a pheromone in the Colorado beetle. Naturwissenschaften 1979, 66, 472-473.

79. Jermy, T.; Butt, B.A. Method for screening females sex-pheromone extracts of the Colorado potato beetle. Entomol. Exp. Appl. 1991, 59, 75-78.

80. Edwards, M.A.; Seabrook, W.D. Evidence for an airborne sex pheromone in the Colorado potato beetle, Leptinotarsa decemlineata. Can. Entomol. 1997, 129, 667-672. 
81. Dubis, E.; Malinski, E.; Dubis, A.; Szafranek, J.; Nawrot, J.; Poplawski, J.; Wrobel, J.T. Sex-dependent composition of cuticular hydrocarbons of the Colorado beetle, Leptinotarsa decemlineata Say. Comp. Biochem. Physiol. A Physiol. 1987, 87, 839-843.

82. Dickens, J.C. Sexual contact influences orientation to plant attractant in Colorado potato beetle, Leptinotarsa decemlineata Say (Coleoptera : Chrysomelidae). Naturwissenschaften 2007, 94, 847-852.

83. Dickens, J.C.; Oliver, J.E.; Hollister, B.; Davis, J.C.; Klun, J.A. Breaking a paradigm: maleproduced aggregation pheromone for the Colorado potato beetle. J. Exp. Biol. 2002, 205, 1925-1933.

84. Hsiao, T.H.; Fraenkel, G. Properties of leptinotarsin: A toxic hemolymph protein from the Colorado potato beetle. Toxicon 1969, 7, 119-128.

85. Bortels, A. A Cation Selective Channel Induced by Two Protein Fractions from the Larval Hemolymph of the Colorado Potato Beetle, Leptinotarsa decemlineata (Say) An Electrophysiological Characterization on Guinea-pig Ventricular Myocytes and on Artificial Membranes; K.U.Leuven: Leuven, Belgium, 1994.

86. Chiou, S.J.; Cerstiaens, A.; Kotanen, S.P.; De Loof, A.; Schoofs, L. Insect larvae contain substances toxic to adults: the discovery of paralysins. J. Insect Physiol. 1998, 44, 405-411.

87. Armer, C.A.; Rao, S.J.Y.; Berry, R.E. Insect cellular and chemical limitations to pathogen development: the Colorado potato beetle, the nematode Heterorhabditis marelatus, and its symbiotic bacteria. J. Invertebr. Pathol. 2004, 87, 114-122.

88. Daloze, D.; Braekman, J.C.; Pasteels, J.M. A toxic dipeptide from the defense glands of the Colorado beetle. Science 1986, 233, 221-223.

89. Hough-Goldstein, J.A.; Geiger, J.; Chang, D.; Saylor, W. Palatability and toxicity of the Colorado potato beetle (Coleoptera, Chrysomelidae) to domestic chickens. Ann. Entomol. Soc. Am. 1993, 86, 158-164.

90. Dickens, J.C. Predator-prey interactions: olfactory adaptations of generalist and specialist predators. Agric. For. Entomol. 1999, 1, 47-54.

91. van Loon, J.J.A.; de Vos, E.W.; Dicke, M. Orientation behaviour of the predatory hemipteran Perillus bioculatus to plant and prey odours. Entomol. Exp. Appl. 2000, 96, 51-58.

92. Weissbecker, B.; Van Loon, J.J.A.; Dicke, M. Electroantennogram responses of a predator, Perillus bioculatus, and its prey, Leptinotarsa decemlineata, to plant volatiles. J. Chem. Ecol. 1999, 25, 2313-2325.

93. Weissbecker, B.; Van Loon, J.J.A.; Posthumus, M.A.; Bouwmeester, H.J.; Dicke, M. Identification of volatile potato sesquiterpenoids and their olfactory detection by the two-spotted stinkbug Perillus bioculatus. J. Chem. Ecol. 2000, 26, 1433-1445.

94. Sant'Ana, J.; Da Silva, R.F.P.; Dickens, J.C. Olfactory reception of conspecific aggregation pheromone and plant odors by nymphs of the predator, Podisus maculiventris. J. Chem. Ecol. 1999, 25, 1813-1826.

95. Lynch, M.E.; Kaplan, I.; Dively, G.P.; Denno, R.F. Host-plant-mediated competition via induced resistance: Interactions between pest herbivores on potatoes. Ecol. Appl. 2006, 16, 855-864. 
96. Gosset, V.; Harmel, N.; Gobel, C.; Francis, F.; Haubruge, E.; Wathelet, J.P.; du Jardin, P.; Feussner, I.; Fauconnier, M.L. Attacks by a piercing-sucking insect (Myzus persicae Sultzer) or a chewing insect (Leptinotarsa decemlineata Say) on potato plants (Solanum tuberosum L.) induce differential changes in volatile compound release and oxylipin synthesis. J. Exp. Bot. 2009, 60, 1231-1240.

97. Brunissen, L.; Vincent, C.; Le Roux, V.; Giordanengo, P. Effects of systemic potato response to wounding and jasmonate on the aphid Macrosiphum euphorbiae (Sternorryncha:Aphididae). J. Appl. Entomol. 2010, 134, 562-571.

98. Panasiuk, O. Response of Colorado potato beetles, Leptinotarsa decemlineata (Say), to volatile components of tansy, Tanacetum vulgare. J. Chem. Ecol. 1984, 10, 1325-1333.

99. Matthews, D.L.; Michalak, P.S.; MacRae, R.J. The Effect of Traditional Insect Repellent Plants on Insect Numbers in a Mixed Planting System. In Proceedings of the 4th International Federation of Organic Agricultural Movements Conference, Resource conserving, environmentally sound agricultural alternatives, Cambridge, MA, USA, 18-20 August 1982.

100. Szendrei, Z.; Rodriguez-Saona, C. A meta-analysis of insect pest behavioral manipulation with plant volatiles. Entomol. Exp. Appl. 2010, 134, 201-210.

101. Dickens, J.C. Orientation of Colorado potato beetle to natural and synthetic blends of volatiles emitted by potato plants. Agric. For. Entomol. 2000, 2, 167-172.

102. Martel, J.W.; Alford, A.R.; Dickens, J.C. Laboratory and greenhouse evaluation of a synthetic host volatile attractant for Colorado potato beetle, Leptinotarsa decemlineata (Say). Agric. For. Entomol. 2005, 7, 71-78.

103. Martel, J.W.; Alford, A.R.; Dickens, J.C. Synthetic host volatiles increase efficacy of trap cropping for management of Colorado potato beetle, Leptinotarsa decemlineata (Say). Agric. For. Entomol. 2005, 7, 79-86.

104. Kuhar, T.P.; Mori, K.; Dickens, J.C. Potential of a synthetic aggregation pheromone for integrated pest management of Colorado potato beetle. Agric. For. Entomol. 2006, 8, 77-81.

105. Dickens, J.C. Plant volatiles moderate response to aggregation pheromone in Colorado potato beetle. J. Appl. Entomol. 2006, 130, 26-31.

106. Martel, J.W.; Alford, A.R.; Dickens, J.C. Evaluation of a novel host plant volatile-based attracticide for management of Colorado potato beetle, Leptinotarsa decemlineata (Say). Crop. Prot. 2007, 26, 822-827.

107. Ragsdale, D.W.; Radcliffe, E.B. Colorado potato beetle management. Available online: http://ipmworld.umn.edu/chapters/ragsdale.htm (accessed on 14 September 2011),

108. Ioannidis, P.M.; Grafius, E.; Whalon, M.E. Patterns of insecticide resistance to azinphosmethyl, carbofuran, and permethrin in the Colorado potato beetle (Coleoptera, Chrysomelidae). J. Econ. Entomol. 1991, 84, 1417-1423.

109. Otálora-Luna, F.; Dickens, J.C. Multimodal stimulation of Colorado potato beetle reveals modulation of pheromone response by yellow light. PLoS ONE 2011, 6, e20990.

110. Otálora-Luna, F.; Dickens, J.C. Spectral preference and temporal modulation of photic orientation by Colorado potato beetle on a servosphere. Entomol. Exp. Appl. 2011, 138, 93-103. 
111. Heuskin, S.; Verheggen, F.J.; Haubruge, E.; Wathelet, J.P.; Lognay, G. The use of semiochemical slow-release devices in integrated pest management strategies. Biotechnol. Agron. Soc. Environ. 2011, 15, 459-470.

112. Hsiao, T.H.; Fraenkel, G. The role of secondary plant substances in the food specificity of the Colorado potato beetle. Ann. Entomol. Soc. Am. 1968, 61, 485-493.

113. Jermy, T.; Butt, B.A.; McDonough, L.; Dreyer, D.L.; Rose, A.F. Antifeedants for the Colorado potato beetle - I. Antifeeding constituents of some plants from the sagebrush community. Insect Sci. Appl. 1981, 1, 237-242.

114. Hare, J.D.; Logan, P.A.; Wright, R.J. Suppression of Colorado potato beetle, Leptinotarsa decemlineata (Say), (Coleoptera: Chrysomelidae) populations with antifeedant fungicides. Environ. Entomol. 1983, 12, 1470-1477.

115. Drummond, F.A.; Casagrande, R.A. Effect of white oak extracts on feeding by the Colorado potato beetle (Coleoptera: Chrysomelidae). J. Econ. Entomol. 1985, 78, 1272-1274.

116. Alford, A.R.; Cullen, J.A.; Storch, R.H.; Bentley, M.D. Antifeedant activity of limonin against the Colorado potato beetle (Coleoptera, Chrysomelidae). J. Econ. Entomol. 1987, 80, 575-578.

117. Kim, M.S.; Lan, Q. Larvicidal activity of $\alpha$-mangostin in the Colorado potato beetle, Leptinotarsa decemlineata. Journal of Pesticide Science 2011, 36, 370-375.

118. Gonzalezcoloma, A.; Reina, M.; Cabrera, R.; Castanera, P.; Gutierrez, C. Antifeedant and toxic effects of sesquiterpenes from Senecio-palmensis to Colorado potato beetle. J. Chem. Ecol. 1995, $21,1255-1270$.

119. Szczepanik, N.; Dams, I.; Wawrzenczyk, C. Feeding deterrent activity of terpenoid lactones with the p-menthane system against the Colorado potato beetle (Coleoptera:Chrysomelidae). Environ. Entomol. 2005, 34, 1433-1440.

120. Gokce, A.; Isaacs, R.; Whalon, M.E. Behavioural response of Colorado potato beetle (Leptinotarsa decemlineata) larvae to selected plant extracts. Pest Manag. Sci. 2006, 62, 1052-1057.

121. Pavela, R.; Sajfrtova, M.; Sovova, H.; Karban, J.; Barnet, M. The effects of extracts obtained by supercritical fluid extraction and traditional extraction techniques on larvae Leptinotarsa decemlineata SAY. J. Essent. Oil Res. 2009, 21, 367-373.

122. Pelletier, Y.; Dutheil, J. Behavioural responses of the Colorado potato beetle to trichomes and leaf surface chemicals of Solanum tarijense. Entomol. Exp. Appl. 2006, 120, 125-130.

123. Yencho, G.C.; Renwick, J.A.A.; Steffens, J.C.; Tingey, W.M. Leaf surface extracts of Solanumberthaultii Hawkes deter Colorado potato beetle feeding. J. Chem. Ecol. 1994, 20, 991-1007.

124. Liu, Y.B.; Alford, A.R.; Bentley, M.D. Effects of epilimonol and starvation on feeding and oviposition by Leptinotarsa-decemlineata. Entomol. Exp. Appl. 1989, 53, 39-44.

125. Murray, K.D.; Groden, E.; Drummond, F.A.; Alford, A.R.; Conley, S.; Storch, R.H.; Bentley, M.D. Citrus limonoid effects on Colorado potato beetle (Coleoptera:Chrysomelidae) colonization and oviposition. Environ. Entomol. 1995, 24, 1275-1283.

126. Szafranek, B.; Synak, E.; Waligora, D.; Szafranek, J.; Nawrot, J. Leaf surface compounds of the potato (Solanum tuberosum) and their influence on Colorado potato beetle (Leptinotarsa decemlineata) feeding. Chemoecology 2008, 18, 205-216. 
127. Jermy, T. Prospects of antifeedant approach to pest-control - a critical review. J. Chem. Ecol. 1990, 16, 3151-3166.

128. Szentesi, A. Antifeedant-treated potato plants as egg-laying traps for the Colorado beetle (Leptinotarsa decemlineata Say, Col., Chrysomelidae). Acta Phytopathol. Hun. 1981, 16, 203-209.

129. Hare, J.D. Suppression of the Colorado potato beetle, Leptinotarsa decemlineata (Say) (Coleoptera:Chrysomelidae), on solanaceous crops with a copper-based fungicide. Environ. Entomol. 1984, 13, 1010-1014.

130. Zehnder, G.; Warthen, J.D. Feeding inhibition and mortality effects of neem-seed extract on the Colorado potato beetle (Coleoptera, Chrysomelidae). J. Econ. Entomol. 1988, 81, 1040-1044.

131. Moreau, T.L.; Warman, P.R.; Hoyle, J. An evaluation of companion planting and botanical extracts as alternative pest controls for the Colorado potato beetle. Biol. Agric. Hortic. 2006, 23, 351-370.

132. Marčić, D.; Perić, P. Field evaluation of natural and synthetic insecticides against Leptinotarsa decemlineata say. Acta Hortic. 2009, 830, 391-396.

133. Alford, R. Deployment strategies for antifeedants in management of Colorado potato beetle. In Advances in Potato Pest Biology and Management; Zehnder, G.W., Powelson, M.L., Jansson, R.K., Raman, K.V., Eds.; APS Press: St Paul, MI, USA, 1994; pp. 342-356.

134. Murray, K.D.; Groden, E.; Drummond, F.A.; Alford, A.R.; Storch, R.H.; Bentley, M.D. Citrus limonoid effects on Colorado potato beetle larval survival and development. Entomol. Exp. Appl. 1996, 80, 503-510.

135. Sinden, S.L. Potato plants make their own insect repellent. Agric. Res. USA 1988, 36, 15.

136. Sinden, S.L.; Sanford, L.L.; Osman, S.F. Glycoalkaloids and resistance to the Colorado potato beetle in Solanum chacoense Bitter. Am. Potato J. 1980, 57, 331-343.

137. Wegorek, W.; Dubniak, H. Reaction of potato leaves to the eggs of the Colorado beetle (Leptinotarsa decemlineata Say). Biuletyn Instytutu Ochrony Roslin 1972, 52, 409-413.

138. Balbyshev, N.F.; Lorenzen, J.H. Hypersensitivity and egg drop: A novel mechanism of host plant resistance to Colorado potato beetle (Coleoptera: Chrysomelidae). J. Econ. Entomol. 1997, 90, 652-657.

139. Guenthner, J.F. Consumer acceptance of genetically modified potaoes. Am. J. Potato Res. 2002, 79, 309-316.

140. Grapputo, A.; Boman, S.; Lindstrom, L.; Lyytinen, A.; Mappes, J. The voyage of an invasive species across continents: genetic diversity of North American and European Colorado potato beetle populations. Mol. Ecol. 2005, 14, 4207-4219.

141. Clark, J.M.; Lee, S.H.; Kim, H.J.; Yoon, K.S.; Zhang, A.G. DNA-based genotyping techniques for the detection of point mutations associated with insecticide resistance in Colorado potato beetle Leptinotarsa decemlineata. Pest Manag. Sci. 2001, 57, 968-974.

142. Boman, S.; Grapputo, A.; Lindstrom, L.; Lyytinen, A.; Mappes, J. Quantitative genetic approach for assessing invasiveness: geographic and genetic variation in life-history traits. Biol. Invasions 2008, 10, 1135-1145.

143. Forister, M.L.; Ehmer, A.G.; Futuyma, D.J. The genetic architecture of a niche: variation and covariation in host use traits in the Colorado potato beetle. J. Evol. Biol. 2007, 20, 985-996. 
144. Pelletier, Y.; Tai, G.C.C. Genotypic variability and mode of action of Colorado potato beetle (Coleoptera : Chrysomelidae) resistance in seven Solanum species. J. Econ. Entomol. 2001, 94, $572-578$.

145. Visser, J.H. Differential sensory perception of plant compounds by insects. ACS symposiums series 208. In Plant Resistance to Insects; Hedin, P.A., Ed. American chemical society: Washington, DC, USA, 1983; pp. 215-230.

(C) 2013 by the authors; licensee MDPI, Basel, Switzerland. This article is an Open Access article distributed under the terms and conditions of the Creative Commons Attribution license (http://creativecommons.org/licenses/by/3.0/). 